\title{
Deacetylated-poly-N-acetylglucosamine-folic Acid as a Nanocarrier for Delivering miR-196a Inhibitor to Anticancer Activity
}

\author{
Yuxia $\mathrm{Hao}^{1} \oplus, \mathrm{Xi}^{2}{ }^{2} \odot$ \\ ${ }^{1}$ Department of Gastroenterology, Shanxi Provincial People's Hospital, Shanxi, China \\ ${ }^{2}$ Department of Lymphoma, Shanxi Bethune Hospital, Shanxi, China
}

Background: MiR-196a is particularly noticeable in the development of liver cancer. However, the rapid degradation by ribonuclease (RNase) imposes a limit on the miRNA gene therapy applications.

Aims: To design a novel gene-targeting nano system for liver cancer treatment

Study Design: Cell culture study and animal experimentation

Methods: Deacetylated (DEAC)-poly-N-acetylglucosamine (PNAG)folic acid (FA) was prepared via ethyl (dimethylaminopropyl) carbodiimide/N-hydroxysuccinimide reaction, and miR-196a inhibitor (miR-196a I)/DEAC-PNAG-FA was prepared through self-assembly. The characterization and nucleic acid protection of the self-assembly system were also determined. The biological function and related mechanism of the prepared system were studied at cellular and molecular levels. Mice were established as a xenotransplantation model to evaluate the anticancer capacity of miR-196a I/DEACPNAG-FA in vivo.

Results: The morphology of miR-196a I/DEAC-PNAG-FA was uniform, and its particle size was approximately 70-100 $\mathrm{nm}$. A nanocarrier with an N/P ratio of 200:1 can maximize the nucleic acid carrying capacity of the self-assembly system. The nanosystem can protect miRNA from RNase degradation and could be internalized rapidly within $4 \mathrm{~h}$. The self-assembly system significantly enhanced the apoptosis-inducing effect of miR-196a I on HepG2 cells $(P=$ $0.003)$. Molecular biological analyses confirmed that the apoptosisinducing effect of the nanosystem was due to the inhibition of miR196a gene expression in HepG2 cells, which upregulate the expression of pro-apoptotic proteins FOXO1 $(P<0.001)$, Bax $(P<0.001)$, Ki67 $(P<0.001)$, and proliferating cell nuclear antigen $(P<0.001)$, and inhibit the expression of apoptosis inhibitory protein $\mathrm{Bcl}-2(P<0.001)$. Moreover, compared with free miR-196a inhibitor or miR-196a I/ DEAC-PNAG, miR-196a I/DEAC-PNAG-FA can more effectively inhibit tumor growth in vivo $(P=0.026)$.

Conclusion: The newly prepared self-assembly targeting system can effectively induce apoptosis and abrogate tumor growth, which may open a new approach for liver cancer treatment.

\section{INTRODUCTION}

The pathogenesis of liver cancer is highly complex, and its occurrence and development are closely related to the abnormal multiple gene expression. Therefore, gene therapy of liver cancer has become an important direction in exploring new methods for clinical liver cancer treatment. ${ }^{1}$ Gene therapy refers to the process of introducing exogenous genes into target cells to treat diseases by compensating for gene defects, repairing gene abnormalities, and enhancing or inhibiting the expression of some genes. MicroRNA (miRNA) can regulate gene expression from multiple levels, thus exhibiting the capability to simultaneously regulate multiple gene proteins and plays multiple roles in liver cancer occurrence and development. ${ }^{2}$ The gene therapy of liver cancer with miRNA as the therapeutic target or agent has developed into a new strategy for malignant tumor treatment. ${ }^{3}$

A type of miRNA, miR-196a, participates in many important human life activities in cells, and the expression disorder is closely related to the occurrence and development of a variety of tumors. ${ }^{4}$ As an oncogene, miR-196a plays an important role in promoting liver cancer invasion, metastasis, and progression. MiR-196a gene inhibition can effectively inhibit the occurrence and development of liver cancer, thereby providing a new target of treatment.

However, traditional anti-hepatoma drugs, such as small molecules, nucleic acids, and proteins, exhibit poor targeting capability and

Corresponding author: Xi Li, Department of Lymphoma, Shanxi Bethune Hospital, Shanxi, China

e-mail: lixi19731973@163.com

Received: August 22, 2021 Accepted: October 27, 2021 Available Online Date: January 18, 2022 • DOI: 10.4274/balkanmedj.galenos.2021.2021-8-62

Available at www.balkanmedicaljournal.org

ORCID iDs of the authors: Y.H. 0000-0002-6844-6071; X.L. 0000-0002-5474-2873.

Cite this article as:

Hao Y, Li X. Deacetylated-poly-N-acetylglucosamine-folic Acid as a Nanocarrier for Delivering miR-196a Inhibitor to Anticancer Activity. Balkan Med J.; 2022; 39 (1):55-65.

Copyright@Author(s) - Available online at http://balkanmedicaljournal.org/ 
have side effects, which easily lead to recurrence, metastasis, and drug resistance. Additionally, the negative surface potential, hydrophilicity, and sensitivity to ribonuclease (RNase) degradation of nucleic acids limit their clinical applications. ${ }^{5,6}$ Deacetylated poly-N-acetylglucosamine (DEAC-PNAG) is a biodegradable biomaterial with good biocompatibility. ${ }^{7,8}$ DEAC-PNAG has a positive surface potential and can form electrostatic interaction with miRNA and other anionic nucleotides. Folic acid (FA) is a kind of vitamin with a small molecular weight. Compared with proteins, such as monoclonal antibodies, FA possessed positive physicochemical properties, low preparation cost, and low immunogenicity. Studies showed that the activity and quantity of folate receptors (FR) on tumor cell membranes are significantly higher than that of normal cells. ${ }^{9,10}$ FR-targeting therapy for cancer has some distinguished advantages, including high folate binding constant, folate modified system that significantly enhances anticancer agent affinity, and radiosensitizers to malignant tumor cells where FR was enriched. ${ }^{11-14}$

The current study developed a safe and effective miRNA-targeting vector based on self-assembly technology (Figure 1). The capability of miR-196a inhibitor-loaded DEAC-PNAG-FA (miR-196a I/ DEAC-PNAG-FA) was tested to form a composite nanosystem and determine its anticancer effects in vitro and in vivo. The objectives of the present study are as follows: describe the characteristics of the self-assembly system, detect its protective capability against RNase, and evaluate the role of cellular uptake and cell function regulation. The self-assembly targeting system was also tested to treat xenograft tumors in mice to verify the therapeutic effects of miR-196a I/DEAC-PNAG-FA on liver cancer in vivo. This study aimed to provide new ideas and theoretical bases for clinical liver cancer treatment.

\section{MATERIAL AND METHODS}

\section{Materials}

Fetal bovine serum (FBS), cell culture medium, and penicillinstreptomycin solution were purchased from Sigma-Aldrich (USA); miR-196a mimics and miR-196a inhibitor from Gene Chem, Co., Ltd. (Shanghai, China); Cy3-labeled miR-196a from Beijing Solarbio Technology Co., Ltd. (Beijing, China); HepG2 cells from American type culture collection (USA); and BALB/C Nude mice from Vital River (Beijing, China).

\section{Preparation of the Self-assembly System}

DEAC-PNAG (molecular weight: 40000) was obtained from Aladdin Biochemical Technology Co., Ltd. (Shanghai, China). DEAC-PNAG (150 mg) was weighed and stirred in a deionized solution for $8 \mathrm{~h}$. Then, $10 \mathrm{ml}$ of N-hydroxysuccinimide (NHS) $(50 \mathrm{mg}$ ) and $10 \mathrm{ml}$ of ethyl (dimethylaminopropyl) carbodiimide (EDC) $(50 \mathrm{mg}$ ) were added. Subsequently, $5 \mathrm{mg}$ of FA was added, $\mathrm{pH}$ was adjusted to 8 , and the reaction was allowed to continue for $12 \mathrm{~h}$. The reaction product was added into the dialysis bag (Molecular weight cutoff: $2000 \mathrm{Da}$ ) and dialyzed with PBS with a $\mathrm{pH}$ of 7.4 for 3 days (the medium was changed every $4 \mathrm{~h}$ ) to remove the unreacted FA. Then dialysis with ultrapure water for
3 days (the medium was changed every $4 \mathrm{~h}$ ) to remove various inorganic salts. MiR-196a inhibitor $(0.4-26 \mu \mathrm{g})$ was added to 110 $\mu \mathrm{L}$ of $50 \mathrm{mM}$ sodium sulfate solution, followed by $\mathrm{NaCl}$. The selfassembly process occurred for 15 min under normal temperature. The DEAC-PNAG-FA nano-polymer mixture was neutralized with $0.5 \mathrm{M} \mathrm{NaOH}$ and vortexed for $10 \mathrm{~s}$. For the RNase A and encapsulation studies, the preparation was formed into granules via centrifugation $\left(15000 \mathrm{rpm}, 4^{\circ} \mathrm{C}, 1 \mathrm{~h}\right.$, Frontier ${ }^{\text {TM}} 5000 \mathrm{MultiPro}$, German) for further analysis. The N/P ratio was calculated using the following formula:

$\mathrm{N} / \mathrm{P}=$ (DEAC-PNAG $* 150$-mole number of amino group)/ (miRNA*44 moles of the phosphoric acid group).

Four different proportions of DEAC-PNAG and miR-196a inhibitors were prepared, i.e., $14.4,3.6,0.9$, and $0.45 \mu \mathrm{g}$ of miR196a I with ratios of 50:1, 200:1, 800:1, and 1600:1, respectively.

\section{Characterization of Nanoparticles}

MiR-196a I/DEAC-PNAG-FA nanoparticles were then suspended in sodium sulfate solution, ultrasound $5 \mathrm{~min}$, and then placed on a copper grid, and covered with $2 \%$ uranyl acetate for 30 s. The samples were washed with ultrapure water, dried in a desiccator, and imaged using a JEOL-1010 transmission electron microscope (JEOL USA, Inc., USA). The size and zeta potential of the nanocomposites were measured via dynamic light scattering (DLS).

\section{Electrophoretic Mobility}

The combination of DEAC-PNAG and miR-196a inhibitor was detected using a 4\% (w/v) agarose E-Gel ${ }^{\circledR}$ iBase $^{\mathrm{TM}}$ system, forming nanocomposites, and adding $20 \mu \mathrm{l}$ of samples to the gel. Electrophoresis was performed following the recommendations of iBase $^{\mathrm{TM}}$. MiR-196a I bands were analyzed using a UVP imaging system (UVP BioDoc-It Imaging System, USA).

\section{Encapsulation Efficiency}

Free miR-196a was used to draw the standard curve to evaluate the encapsulation efficiency of DEAC-PNAG-RGD for miRNA. Different concentrations of miR-196a underwent electrophoresis for $30 \mathrm{~min}$ in $4 \%(\mathrm{w} / \mathrm{v})$ Invitrogen E-Gel prefabricated agarose gel electrophoresis system. Simultaneously, 4\% SDS-treated nanocomposites were dissolved in the same gel. A gel doc system was used to analyze the gel, and the standard curve was generated following the band strength. The entrapped RNA concentration was calculated.

\section{RNase A Protection Test}

The nanocomposites and free miR-196a inhibitor were treated with $0.18 \mu \mathrm{g}$ of RNase $\mathrm{A}$ at $37^{\circ} \mathrm{C}$ for $1 \mathrm{~h}$ to evaluate the protective effect of DEAC-PNAG on miRNA. The composite nanoparticles were centrifuged $(15000 \mathrm{rpm})$ and treated with $4 \mathrm{ml}$ of ethylenediaminetetraacetic acid disodium salt $(0.20 \mathrm{M})$ for 10 min. The collected miR-196a I/DEAC-PNAG-FA nanoparticles were then suspended in $2 \%$ sodium dodecyl sulfate and placed for $30 \mathrm{~min}$ before conducting gel electrophoresis. The treated 
nanocomposites and free miR-196a inhibitor were subjected to gel electrophoresis for $30 \mathrm{~min}$ in Invitrogen E-Gel prefabricated agarose gel electrophoresis system and was then analyzed.

\section{Cell Experiment}

\section{Cytotoxicity and Cell Apoptosis}

The cells were cultured in RPMI 1640 medium that was supplemented with $10 \%$ FBS for 3 days. HepG2 cells in the logarithmic growth phase were divided into three groups: miR196a I, miR-196a I/DEAC-PNAG, and miR-196a I/DEAC-PNAGFA. The equivalent concentrations of miR-196a inhibitor were $120,100,80,60,40$, and $20 \mathrm{nM}$. The drug-free group was used as the positive control, and each concentration was set with five parallel wells. After 24, 48, and $72 \mathrm{~h}$ of continuous culture, the MTT method was used for detection. The measured experimental data were inputted into GraphPad Prism 7 software for analysis and processing. Cell survival rate was calculated.

HepG2 cells were treated with miR-196a I, miR-196a I/DEACPNAG, and miR-196a I/DEAC-PNAG-FA for $48 \mathrm{~h}$. The equivalent concentrations of miR-196a inhibitor were $60 \mathrm{nM}$. The cells were washed twice with cold PBS and added $5 \mu 1$ of Annexin V-FITC and incubated at $2{ }^{\circ} \mathrm{C}-8{ }^{\circ} \mathrm{C}$ for $15 \mathrm{~min}, 5 \mu \mathrm{l}$ of PI was added, incubated at $2{ }^{\circ} \mathrm{C}-8{ }^{\circ} \mathrm{C}$ in dark for $5 \mathrm{~min}$, and wash twice by the binding buffer solution. Flow cytometry was used to measure the apoptosis rate within $60 \mathrm{~min}$ after preparation, and Cell Quest software was used to analyze and calculate the data. The experiment was repeated three times and the average value was taken.

\section{Fluorescence Microscopy}

Cy3-labeled miR-196a I (Cy3-miR-196a I, red) was used for uptake and DAPI (blue) for re-staining. HepG2 cells were treated with miR-196a I, miR-196a I/DEAC-PNAG, and miR-196a I/ DEAC-PNAG-FA nanocomposites with a molar concentration of $60 \mathrm{nM}$ for $4 \mathrm{~h}$. The cells were washed with PBS and fixed with 4\% paraformaldehyde (PFA) for $20 \mathrm{~min}$. After the PFA removal, DAPI FluoroQuest ${ }^{\mathrm{TM}}$ with an anti-fading fixing medium (AAT Bioquest, Inc., USA) was used and placed on a glass slide. Fluorescence images were obtained using an Eclipse Ti-E Inverted Microscope System (Nikon, Japan).

\section{In Vitro Uptake and Quantitative Real-time Reverse Transcription-polymerase Chain Reaction (RT-PCR) of the Nanosystem}

HepG2 cells were cultured in 96 wells with a density of $1.0 \times 10^{5}$ cells per well. The cells were cultured for $12 \mathrm{~h}$ and then treated with $25 \mu \mathrm{L}$ of nano-suspension for $24 \mathrm{~h}$. MiRNA was isolated using the miRNeasy Mini Kit (Qiagen217004, Netherlands). The RNA integrity assessment used BioTek Gen5 ${ }^{\mathrm{TM}}$ Take ${ }^{\mathrm{TM}}$ software to read and analyze the data. With the miScript II RT Kit (QIAGEN, Netherlands), $1 \mu \mathrm{g}$ of miRNA was used for complementary DNA (cDNA) synthesis. The cDNA products were amplified using the QuantiNova SYBR Green PCR Kit. RT-PCR system (Bio-Rad Laboratories, Inc., USA) was used to evaluate the change of miR-196a in HepG2 cells, whereas
RNU6B for internal control. RT-PCR primers were synthesized by Guangzhou Ruibo Biotechnology Co., Ltd. (China). Primers used in this study are shown in Table 1.

\section{Western Blotting}

Hep2G cells were seeded in six-well plates and incubated with nanocomposites containing $1.0 \mu \mathrm{g}$ of miR-196a I/DEACPNAG-FA at a ratio of 200:1 for $48 \mathrm{~h}$. RIPA buffer with protease inhibitor and phosphatase inhibitor (Biyuntian, China) was used for pyrolysis and a BCA protein assay kit (Biyuntian, China) to determine the total protein concentration. After the electrophoresis at a constant pressure of $120 \mathrm{~V}$ to the bottom of the separation gel, it was transferred to the nitrocellulose membrane and sealed for $2 \mathrm{~h}$. Then, 1:1000 diluted Ki76, proliferating cell nuclear antigen (PCNA), FOXO1, Bax, and Bcl-2 or 1:3000 diluted Glyceraldehyde 3-phosphate dehydrogenase (GAPDH) antibodies (CST Company, USA) were added. Then, incubated overnight at $4{ }^{\circ} \mathrm{C}$ and washed three times with PBST for 15 min each time. Subsequently, a secondary antibody IRDye (1:10000) was added for $1 \mathrm{~h}$. The sample was washed three times with PBST, and its color was developed using an electrochemiluminescence reagent. The sample was exposed, and photographs were taken.

\section{Xenotransplantation Model and Antitumor Activity In Vivo}

\section{Establishment and Grouping of Mouse Liver Cancer Model}

After the Hep2G cell resuscitation, the cells in the logarithmic growth stage were taken, digested with pancreatin, collected in a centrifuge tube, centrifuged at $1000 \mathrm{rpm}$ for $5 \mathrm{~min}$, discarded the supernatant, and washed twice with PBS. The cells were resuspended with PBS and counted with a cell counting plate for a cell density of $2 \times 10^{7}$ cell $/ \mathrm{ml}$ in suspension.

$\mathrm{BALB} / \mathrm{C}$ nude mice were subcutaneously inoculated with $100 \mu \mathrm{l}$ of cell suspension. After the skin disinfection of nude mice, 100 $\mu \mathrm{l}$ cell suspension was subcutaneously inoculated on the back of the neck using a $1 \mathrm{ml}$ syringe. The subcutaneous tumor of nude mice was round, regular, and easy to observe and measure. One week after inoculation, 24 tumor-bearing mice with clear tumor boundaries and uniform tumor diameter were randomly divided into 4 groups according to tumor volume (TV). The groups are as follows (6 mice per group): miR-196a I, miR-196a I/DEACPNAG, miR-196a I/DEAC-PNAG-FA, and saline group. The injection dose of miR-196a I in each group was at $1.2 \mathrm{nmol}$ per mouse, every 3 days, by tail vein for 21 consecutive days. The Ethics Committee of Shanxi Bethune Hospital approved the experiment and supervised and guided the whole experimental process (No.201909034).

TABLE 1. List of Primers

\begin{tabular}{ll}
\hline miR-196a & F: CGTCAGAAGGAATGATGCACAG \\
& R: ACCTGCGTAGGTAGGTTTCATGT \\
RNU6B & F: CTCGCTTCGGCAGCACA \\
& R: AACGCTTCACGAATTT
\end{tabular}




\section{Antitumor Activity In Vivo}

The TV and the weight of mice were measured every 3 days. Before administration, the TV was measured with a vernier caliper. Until the end of the administration, the average value of each group was taken and the tumor growth curve was drawn. At the end of the experiment, the mice were euthanized, the tumor was completely dissected and weighed, and the tumor inhibition rate was calculated according to the formula $\mathrm{TV}: \mathrm{V}=(\mathrm{L} \times \mathrm{W} 2) / 2$, where $\mathrm{W}$ and $\mathrm{L}$ represent the width and length of the tumor, respectively. The evaluation index of antitumor activity in tumor inhibition rate $=(\mathrm{Wc} \times \mathrm{Wt}) \div \mathrm{Wc} \times 100 \%$, in which $\mathrm{Wc}$ and $\mathrm{Wt}$ represent tumor weight of control group and administration group, respectively. Relative TV $(\mathrm{RTV})=\mathrm{Vt} / \mathrm{Vo}$, in which $\mathrm{Vo}$ is the TV measured during caged administration and $\mathrm{Vt}$ is the TV measured at each time.

\section{Statistical Analysis}

GraphPad Prism 7 software was used for data processing, and data were expressed as mean \pm standard deviation. The ShapiroWilk test showed that data had a normal distribution. Statistically significant differences between 3 or more groups were analyzed using the one-way analysis of variance followed by multiple comparisons using Dunnett's T3 test. The power calculation was performed based on the multiple Dunnett test $(\alpha=0.05, \beta=0.2)$. According to our primer experimental setup (6 treatments with 6 replicates, 12 controls for miR-196a I/DEAC-PNAG and miR196a I/DEAC-PNAG-FA groups), the effect size of 0.1438 and statistical power of 0.8607 was estimated. Statistical analyses were performed using International Business Machines Statistical Package for the Social Sciences v23.0 with the significance level set at $\alpha=0.05$.

\section{RESULTS}

\section{Characterization of miR-196a I/DEAC-PNAG-FA and its Protective Effect on miRNA}

MiR-196a I degradation was observed in the RNase A incubated groups (60 min co-culture) at N/P ratios of 50:1, 200:1, and 800:1, whereas significant degradation was observed in the RNase A incubated groups at an N/P ratio of 1600:1 (Figure 2a, Table 2). Density analysis showed that DEAC-PNAG-FA at N/P ratios of $50: 1,200: 1$, and $800: 1$ protected nearly $90 \%$ of miRNA from degradation (Figure 2a, Table 2). Agarose gel electrophoretic mobility shift assay showed that miR-196a I was completely bound to DEAC-PNAG-FA at all concentrations and could not migrate through the gel matrix (Figure 2b). The 200:1 and 800:1 N/P ratio groups revealed that approximately $80 \%$ of miR-196a inhibitor was encapsulated, whereas approximately $55 \%-65 \%$ of miR-

TABLE 2. Gene Protection of Nanosystem with Different N/P Ratio

\begin{tabular}{llllll}
\hline & \multicolumn{5}{c}{ N/P ratio } \\
\cline { 2 - 6 } Group & $0: 1$ & $50: 1$ & $200: 1$ & $800: 1$ & $1600: 1$ \\
Rnase A+ & 0.00 & 0.97 & 0.95 & 0.86 & 0.42 \\
Rnase A- & 1.00 & 1.00 & 1.00 & 1.00 & 1.00 \\
\hline
\end{tabular}

196a $\mathrm{I}$ in the 50:1 and 1600:1 N/P ratio groups (Figure 2c). Then, the 200:1 N/P ratio group was characterized. Based on the DLS analysis, the DEAC-PNAG-FA polymer was observed as round or oval, with an average particle size of approximately $74 \mathrm{~nm}$ (Figure 2e), a zeta potential of $+21.4 \mathrm{mV}$, and a polydispersity index of 0.162 , indicating that miR-196a I/DEAC-PNAG-FA exhibited high dispersion. Transmission electron microscopy imaging further confirmed that the 200:1 N/P ratio group was spherical and monodisperse (Figure 2d).

\section{Cytotoxicity and Apoptosis}

Figure 3a shows that the cell survival rates of miR-196a I/DEACPNAG and miR-196a I/DEAC-PNAG-FA were significantly decreased ( $p=0.923, p=0.001, p=0.004, p=0.005, p=0.002, p=$ 0.010 from concentration $20 \mathrm{nM}$ to $120 \mathrm{nM}$, respectively) compared with that of free miR-196a I at corresponding concentrations. Meanwhile, the cell survival rate of the miR-196a I/DEAC-PNAGFA group was significantly decreased $(p=0.039, p=0.004, p=$ 0.001 at time for 24,48 , and $72 \mathrm{~h}$, respectively) in a time-dependent manner compared with that of the miR-196a I /DEAC-PNAG group (Figures 3a and 3b).

The Apoptosis Rates of the miR-196a I/DEAC-PNAG and miR-196a I/DEAC-PNAG-FA groups were significantly increased $(p=0.003)$ compared with that of miR-196a inhibitor (Figures 3c and 3d). Meanwhile, the apoptosis rate of the miR-196a I/DEACPNAG-FA group was significantly increased $(p=0.014)$ compared with that of the miR-196a I/DEAC-PNAG group (Figures 3c and 3d). After the FA incorporation, the enhancement of apoptosis induction was consistent with the cytotoxicity test results.

\section{Cellular Uptake}

Fluorescent-labeled miRNA-196a I-Cy3, miRNA-196a I-Cy3/ DEAC-PNAG, and miRNA-196a I-Cy3/DEAC-PNAG-FA complexes were cultured with Hep2 $\mathrm{G}$ cells for $4 \mathrm{~h}$ to confirm the cell uptake of anti-miRNA promotion by the nanocomposites. Cy3 positive cells were observed in the 200:1 N/P ratio group. Contrarily, no Cy3 fluorescence was observed in the cells that were incubated only with miR-196a I-Cy3 (Figure 4a). Meanwhile, the cell uptake capability of FA-loaded nanoparticles was significantly enhanced $(P<0.047)$.

\section{Quantitative RT-PCR Analyses}

RT-PCR was performed to further quantify the delivery of miRNA I and mimics after Hep2 $\mathrm{G}$ cell treatment with the nanocomposites. The expression of miR-196a I in the miR-196a I/DEAC-PNAG-FA group was significantly lower than that in the control group (Figure 4b). Meanwhile, the miR-196a mimics/DEAC-PNAG-FA group significantly increased the expression of miR-196a (Figure 4c). These data indicate that the DEAC-PNAG complex can effectively deliver miRNA to change its expression in vitro, and the addition of FA enhances the delivery of the DEAC-PNAG complex.

\section{Expression of Apoptosis-related Proteins}

The Western blot results are presented in Figure 5. All proteins were corrected based on the internal reference protein GAPDH. MiR- 
196a I can significantly upregulate pro-apoptotic protein FOXO1 (Figure 5a) and Bax (Figure 5b) expression levels and downregulate the expression of apoptosis inhibitory protein Bcl-2 (Figure 5c) after $48 \mathrm{~h}$ of treatment with miR-196a I at a concentration of $60 \mathrm{nM}$ and the nano system with the same concentration of miR-196a I $(P<0.05)$. Additionally, along with the downregulation of miR$196 \mathrm{a}$, the expression of cell proliferation-related proteins Ki76 (Figure 5d) and PCNA (Figure 5e) were decreased. Compared with the free drug group, miR-196a I/DEAC-PNAG can improve the regulatory effect of miR-196a I on apoptotic proteins (Figure 5f, FOXO1 $[P<0.001]$, Bax $[P<0.001]$, Ki67 $[P<0.001]$, PCNA $[P<0.001]$, and Bcl-2 $[P<0.001 \backslash)$. Additionally, the FA introduction enhanced the miR-196a I/DEAC-PNAG regulation on apoptotic proteins (Figure 5f, FOXO1 $[P<0.001]$, Bax $[P<0.001], \mathrm{Ki} 67[P<0.001]$, PCNA $[P<0.001]$, and Bcl-2 $[P<$ $0.001])$. This finding is consistent with the RT-PCR results.

\section{Xenotransplantation Model and Tumor Growth Inhibition In Vivo}

The tumor inhibition rate of the miR-196a I/DEAC-PNAG-FA group was $71.9 \%$, which was significantly higher than that of $58.7 \%$ in miR-196a I/DEAC-PNAG and $43.3 \%$ in the miR-196a I groups ( $p=0.002$ ) (Figure $6 \mathrm{a}, \mathrm{b})$. In this study, $100 \mu \mathrm{l}$ of cell suspension was subcutaneously inoculated on the back of BALB/C nude mice, the weight of mice in the saline group rapidly increased, and the weight of mice in miR-196a I, miR-196a I/DEAC-PNAG, and miR-196a I/DEAC-PNAG-FA groups decreased in varying degrees, of which miR-196a I decreased the most due to drug toxicity, while the drug-loaded DEAC-PNAG-FA nano complex alleviated the toxicity of miR-196a I to mice (Figure 6c). The $\mathrm{TV}$ on the back of mice continuously increased with time. In the free miR-196a I group, the growth trend of TV in the miR-196a I/ DEAC-PNAG and miR-196a I/DEAC-PNAG-FA group decreased

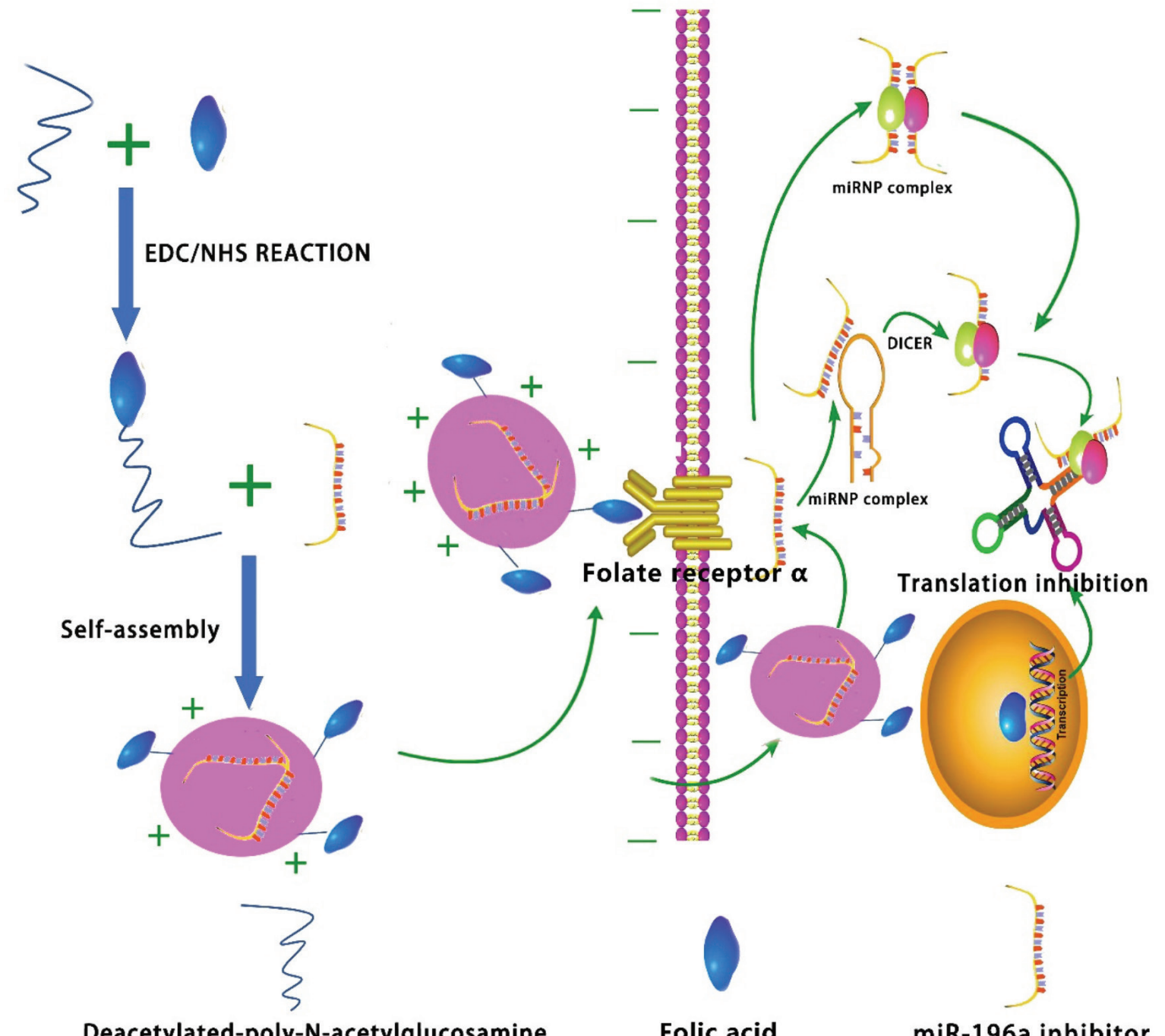

FIG. 1. A self-assembly system that targets miR-196a I for the gene therapy of liver cancer was designed. Deacetylated (DEAC)-poly-Nacetylglucosamine (PNAG)-folic acid (FA) was prepared via EDC/NHS reaction, and then miR-196a I/DEAC-PNAG-FA was prepared through selfassembly. Modified synthetic miR-196a I specifically inhibits individual miR-196a, thereby promoting the HepG2 cell apoptosis. 
significantly (Figure 6d). The latter has the highest antitumor effects $(p=0.017)$.

\section{DISCUSSION}

At present, many groups of clinical and experimental data have reported the regulatory role and mechanism of miR-196a in liver cancer pathogenesis. MiR-196a is highly expressed in the tissues and serum of patients with liver cancer, which is abnormally increased due to hepatitis $\mathrm{B}$ and $\mathrm{C}$ viruses. ${ }^{15,16}$ Darda et al. ${ }^{17}$ found that miR-196a affects the expression of $\mathrm{p} 53$, hoxb9, and
Hoxb8 miRNA and proteins in hepatoma cells and plays the role of a tumor-promoting factor. Yang et al. ${ }^{18}$ found miR-196a was highly expressed in the hepatoma cell lines Huh7, MHCC-97H, Hep3B, HepG2, and SMMC-7721 compared with human normal primary hepatocytes, and the miR-196a mechanism was further explored by transfecting the miR-196a I and its negative control. The miR-196a expression reduces the activity and clone-forming capability of cancer cells, promotes apoptosis, and inhibits the invasion and metastasis of cancer cells. This biological process is achieved through the targeted regulation of FoxO1 by miR-196a.

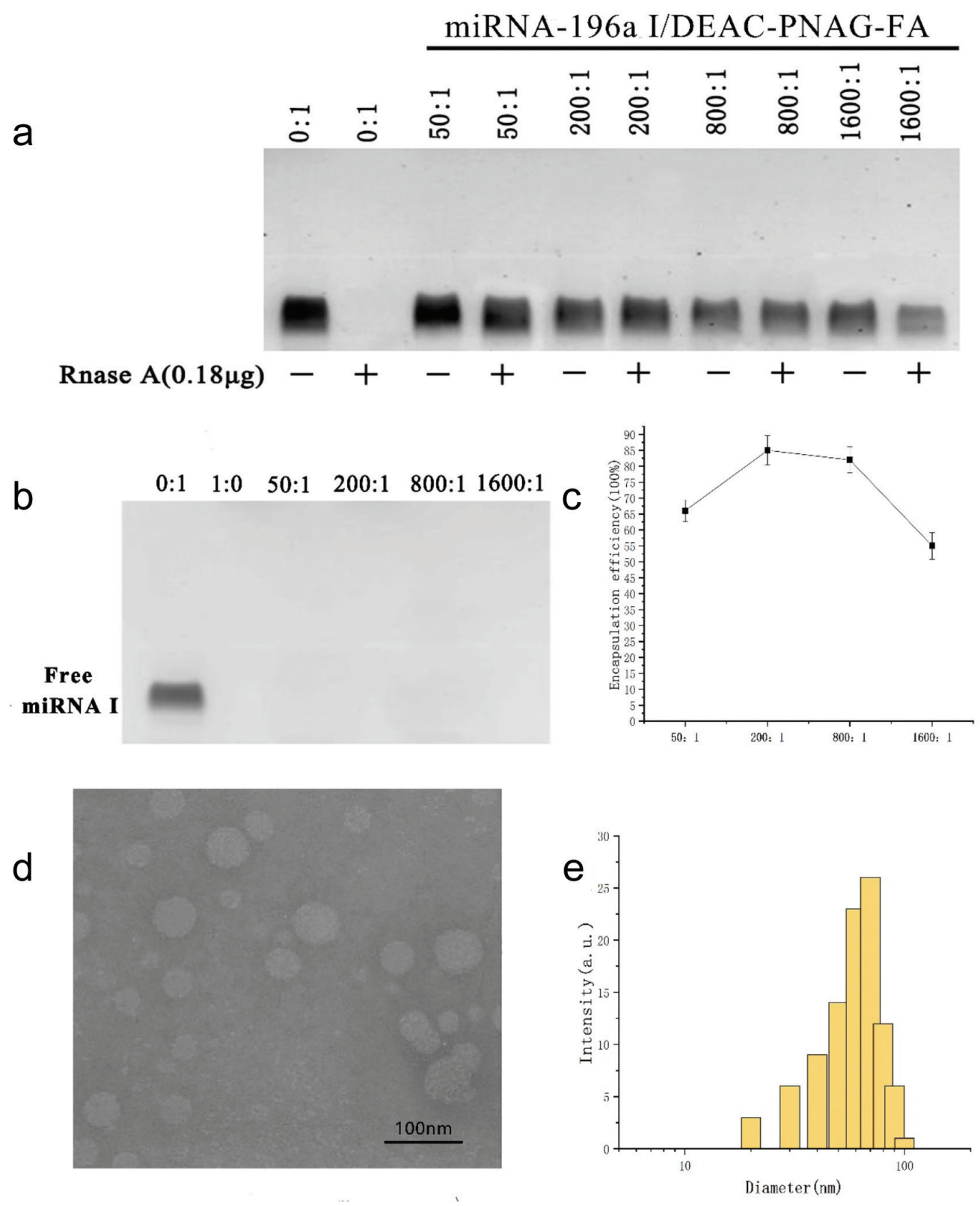

FIG. 2 a-e. Characterization of miR-196a I/DEAC-PNAG-FA and its protective effect on anti-miRNA

(a) The $50: 1,200: 1,800: 1$, and 1600:1 N/P ratio groups were incubated for $1 \mathrm{~h}$ at $37^{\circ} \mathrm{C}$ with or without RNase A (0.18 $\left.\mu \mathrm{g}\right)$; (b) Gel retardation of DEAC-PNAG-FA on miRNA-196a inhibitor; and (c) The standard curve based on Image $\mathrm{J}$ and GraphPad is used to quantify encapsulation efficiency. (d) MiR-196a I/DEAC-PNAG-FA nanoparticles were observed via TEM. (e) The size distribution of miR-196a I/DEAC-PNAG-FA nanoparticles was measured via DLS. 
These results indicate that miR-196a plays an important role in the pathogenesis of hepatocellular carcinoma by regulating the expression of a variety of downstream genes.

MiRNA therapy requires an effective platform to introduce miRNA into cells. ${ }^{19,20}$ At present, a nanometer system, including PLGA, liposomes, and graphene oxide, has been applied to miRNA loading. However, the application value is limited due to the complex assembly and low efficiency of nucleic acid transfer in vivo and in vitro. ${ }^{21-23}$ The DEAC-PNAG polymer exhibits potential advantages as a miRNA delivery platform in cancer. As a miRNA carrier, the DEAC-PNAG polymer can effectively embed miRNA and protect it from RNase degradation, which is extremely important to ensure the stability of miRNA in vivo environment. Additionally, the nanocomposite diameter ( $\sim 200 \mathrm{~nm}$ ) enables it to avoid absorption by the liver and the reticuloendothelial system during circulation. Meanwhile, its cationic zeta potential indicates that it exhibits moderate stability. $^{24,25}$ However, its targeting effect is limited, thus modifying the drug delivery system is necessary to improve its targeting capability.

FR is a glycoprotein linked to the cell membrane by glycosylphosphatidylinositol, which can bind and transcribe folate and its derivatives on the cell surface. In vivo, FR mainly exists in three subtypes: FR $\alpha, \mathrm{FR} \beta$, and FR $\gamma$. Among them, the expression
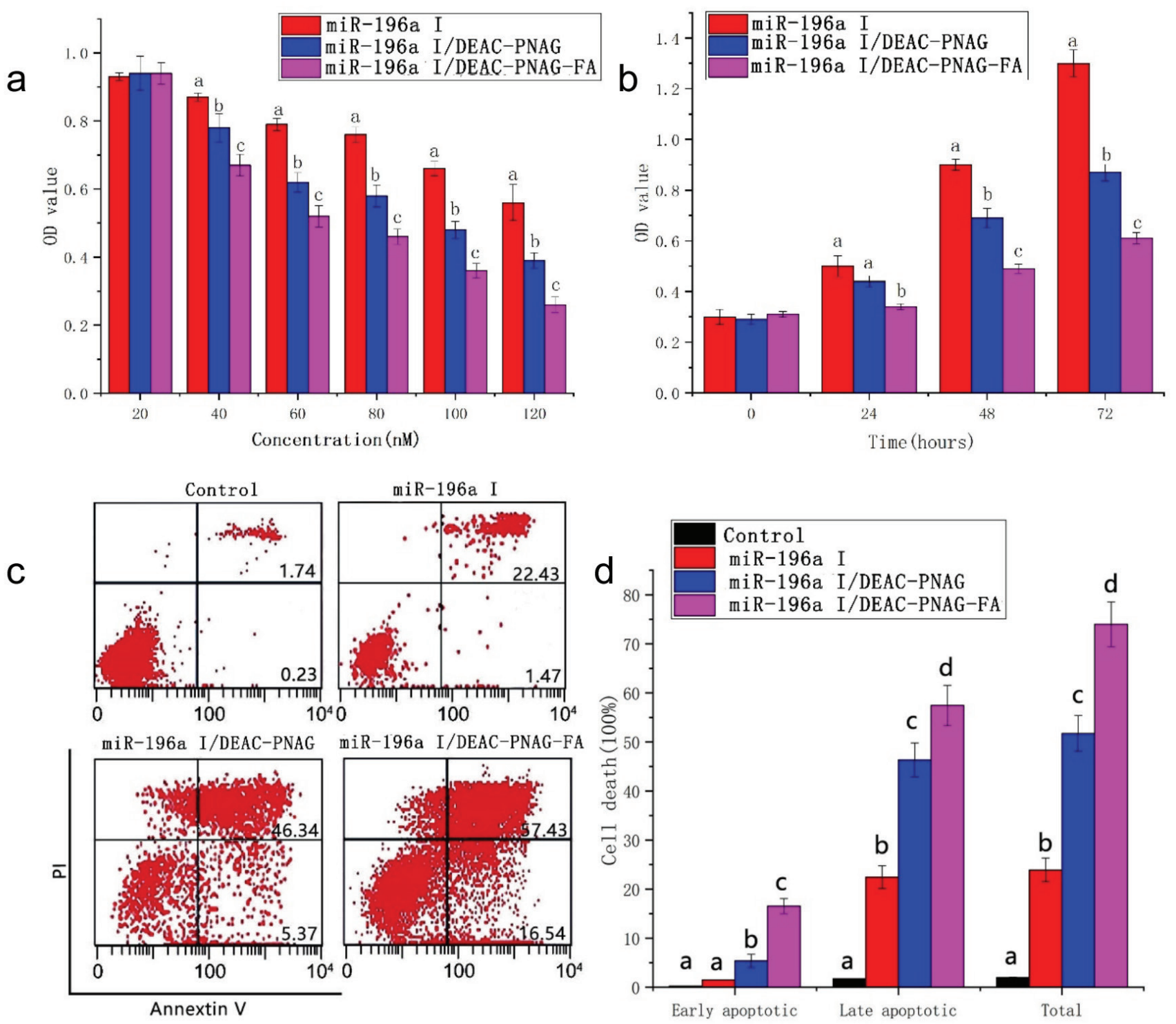

FIG. 3 a-d. Detection of cell survival and apoptosis rates

a: Effects of different concentrations of miR-196a inhibitor, miR-196a I/DEAC-PNAG, and miR-196a I/DEAC-PNAG-FA on survival rate at 48 h. b: Effects of miR-196a inhibitor at $60 \mathrm{nM}$, miR-196a I/DEAC-PNAG, and miR-196a I/DEAC-PNAG-FA on cell survival rate at 24, 48, and 72 h. c and d: The effects of miR-196a I, miR-196a I/DEAC-PNAG, and miR-196a I/DEAC-PNAG-FA pretreatment on the apoptosis rate of HepG2 cells.

*a, b, c, and d: different letters represent statistical significance $(P<0.05)$ 
of FR $\alpha$ has a clear tissue specificity and selectivity and is lowly expressed in healthy cells, tissues, and organs but highly expressed in most tumor tissues and cells, such as liver, cervical, breast, brain, colon, rectal, etc. ${ }^{26,27}$ Combining the carrier with FA to selectively inhibit cancer cells, in which FR $\alpha$ is highly expressed, can greatly reduce the side effects of traditional chemotherapy drugs and achieve drug targeting effect. ${ }^{28}$ The current study used FA-modified DEAC-PNAG particles as the research object to optimize a DEAC-PNAG-FA nanosystem that exhibits tumortargeting to achieve a targeted nanosystem with high drug loading and gene protection.
Our data indicate that the miR-196a I/DEAC-PNAG-FA complex can effectively transfer anti-miRNA into cells, leading to cell function changes. A significant correlation was found between the number of delivered anti-miRNA in cells and the increased expression level of miR-196a in HepG2 cells. The 200:1 N/P ratio of the nanocomposite can provide the best anti-miRNA protection and generate good anti-miRNA activity in cells. Studies showed that a nanosystem with a low concentration of miRNA may hinder the release of miRNA from the nanocomposites, resulting in miRNA functional damage. ${ }^{29}$ Notably, the concentration of 200:1 self-assembly system can deliver complete anti-miRNA to cells and allow anti-miRNA to
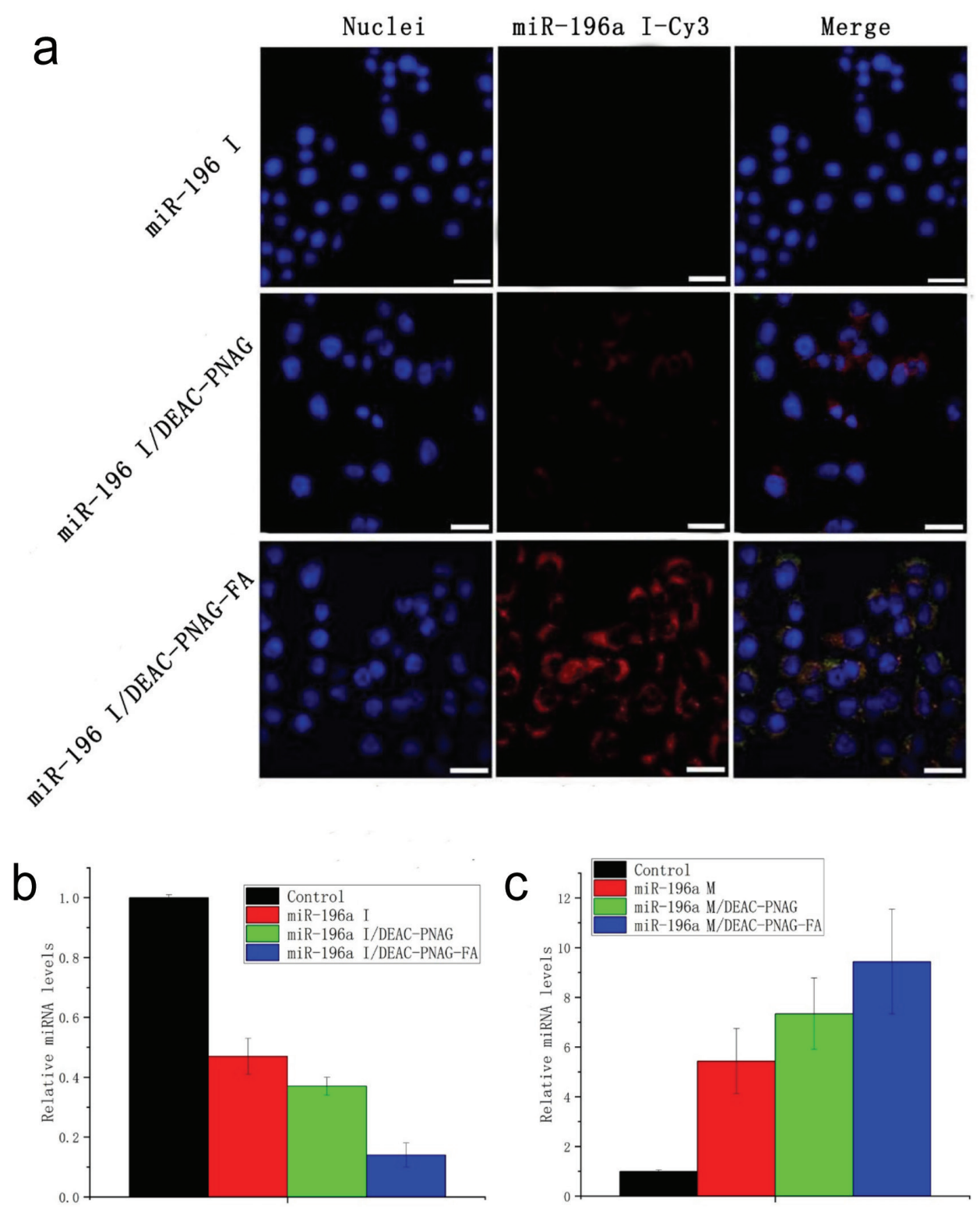

FIG. 4 a-c. In vitro cellular uptake and functional gene expression

a: The uptake of Cy3-labeled miR-196a I (miR-196a I-Cy3, red) in Hep2G cells cultured at $37^{\circ} \mathrm{C}$ for $4 \mathrm{~h}$ were analyzed via fluorescence microscopy. The nuclei were stained with DAPI (blue). b: The expression of miR-196a in HepG2 cells treatment by miR-196a inhibitor groups; c: The expression of miR-196a in HepG2 cells treatment by miR-196a mimics groups. 
be separated from the complex and inhibit the gene expression of miR-196a.

MiRNA is a highly conserved small RNA molecule that regulates gene expression and has a gene regulatory function that regulates the expression of multiple downstream genes after transcription. ${ }^{30-32}$ Our study results showed that miR-196a inhibitor was delivered into the hepatoma cells by the targeting nanosystem, and the expression level of miR-196a was significantly downregulated,

FOXO1
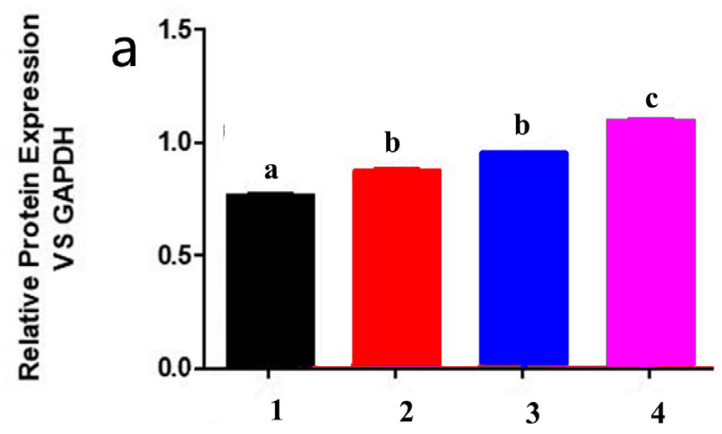

Bcl-2
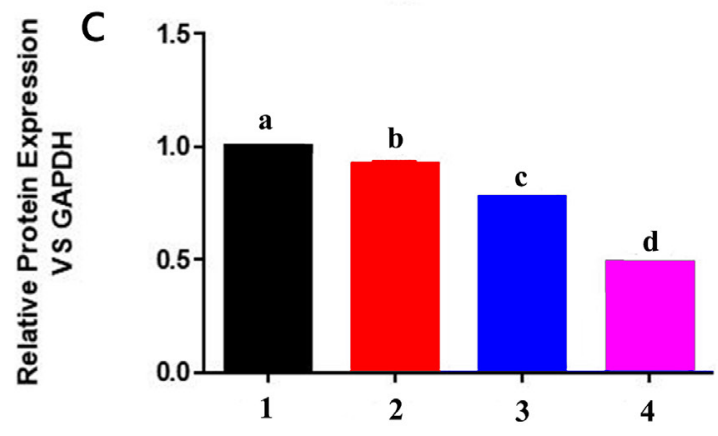

PCNA

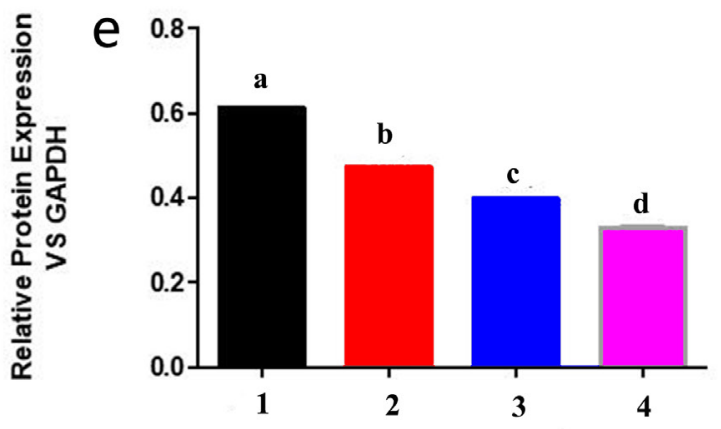

which can significantly downregulate Bcl-2, Ki76, and PCNA, and upregulate the expression levels of FOXO1 and $\mathrm{Bax}(P<$ 0.05). Compared with the free drug group, miR-196a I/DEACPNAG-FA can improve the regulatory effect of miR-196a I on cell proliferation and apoptosis proteins $(P<0.05)$. Additionally, the introduction of FA enhanced the regulation of miR-196a I/DEACPNAG-FA $(P<0.05)$. This finding is significantly correlated with the aforementioned results. Xenograft nude mice model was subcutaneously injected with HepG2 cells and then intravenously

Bax

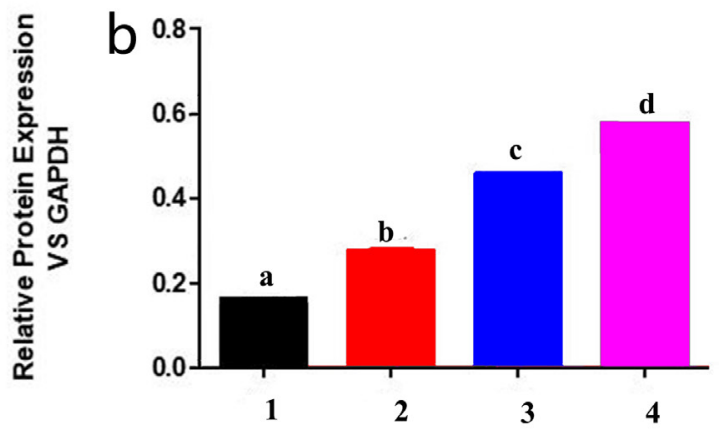

Ki67
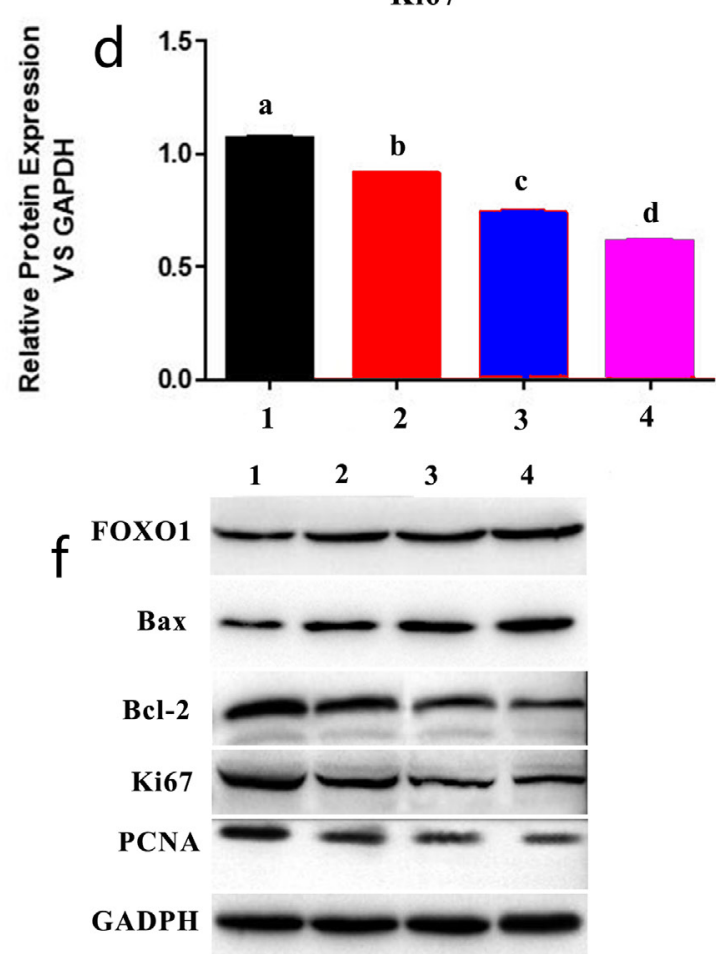

FIG. 5 a-e. MiR-196a I/DEAC-PNAG-FA (200:1) mediates the regulation of apoptosis proteins in HepG2 cells. Numbers 1, 2, 3, and 4 represent the control, miR-196a I, miR-196a I/DEAC-PNAG, and miR-196a I/DEAC-PNAG-FA groups. a: The quantitative analysis of FOXO1 after MiR-196a I/ DEAC-PNAG-FA (200:1) treatment for 48 hours; b: The quantitative analysis of Bax after MiR-196a I/DEAC-PNAG-FA (200:1) treatment for 48 hours; c: The quantitative analysis of Bcl-2 after MiR-196a I/DEAC-PNAG-FA (200:1) treatment for 48 hours; d: The quantitative analysis of Ki67 after MiR196a I/DEAC-PNAG-FA (200:1) treatment for 48 hours; e: The quantitative analysis of PCNA after MiR-196a I/DEAC-PNAG-FA (200:1) treatment for 48 hours; f: Expression levels of apoptosis proteins and GAPDH following MiR-196a I/DEAC-PNAG-FA (200:1) treatment detected by western blot technique.

${ }^{*} \mathrm{a}, \mathrm{b}, \mathrm{c}, \mathrm{d}$ : different letters represent statistical significance $(P<0.05)$ 

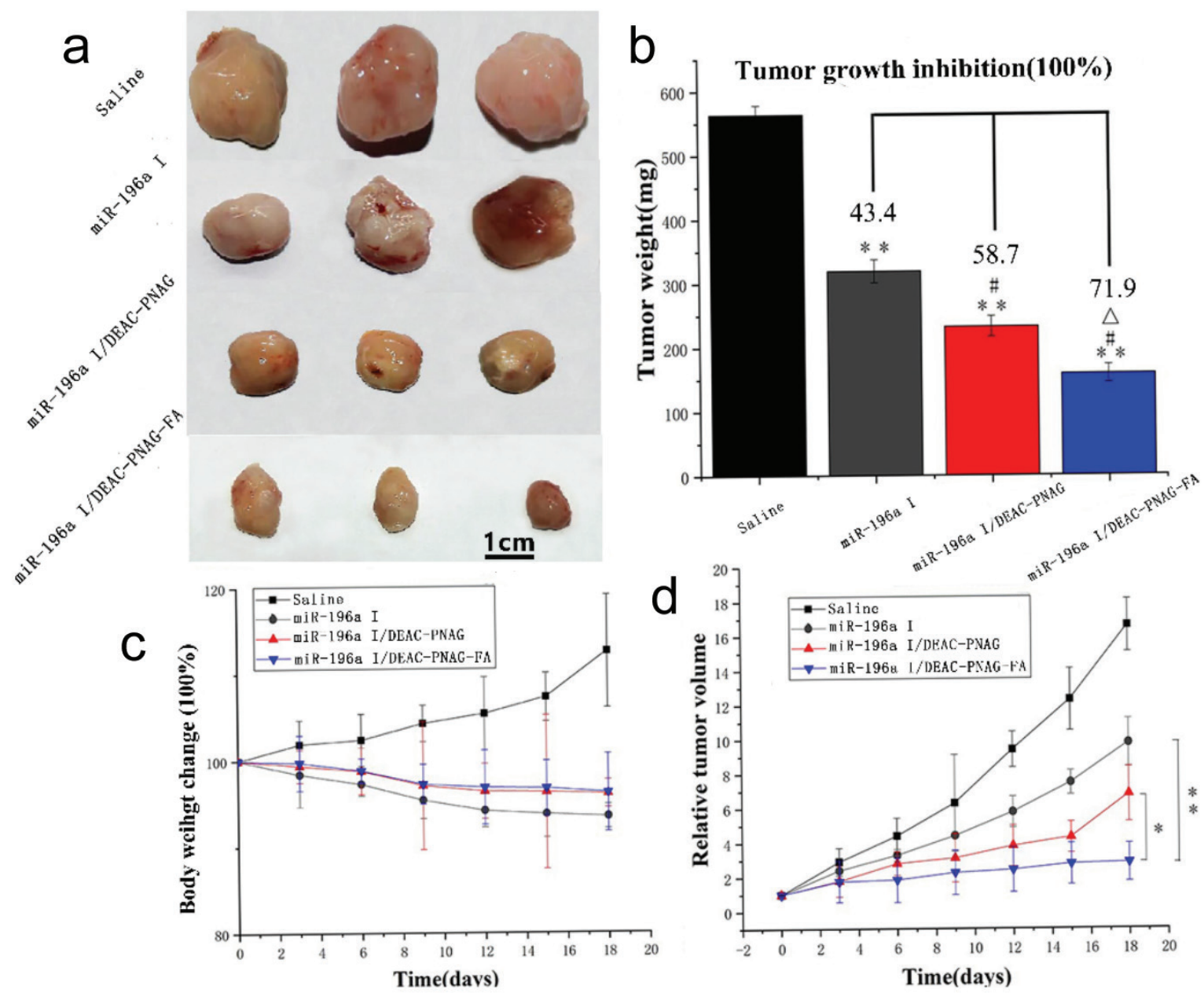

FIG. 6 a-d. Inhibitory effect of each experimental group on the growth of HepG2 in subcutaneously transplanted nude mice. A: Tumor images after resection were displayed at the same magnification in each treatment group; B: Tumor weight and tumor growth inhibition of each group at the end of the experiment. ${ }^{* *}$ Compared with Saline, $P<0.01$; \#Compared with miR-196a I, $p<0.05$; $\triangle$ Compared with miR-196a I/DEAC-PNAG, $P<0.05$; C: Weight analysis of tumor-bearing mice; D: RTV analysis of each experimental group. Compared with miR-196a I/DEAC-PNAG-FA $P<0.05$ ${ }^{* *} P<0.01$.

with miR-196a I/DEAC-PNAG-FA to prove the therapeutic effect in vivo. Compared with free miR-196a inhibitor and miR-196a I/ DEAC-PNAG, the miR-196a I/DEAC-PNAG-FA showed higher tumor-killing efficiency.

In conclusion, DEAC-PNAG-FA nano-systems are feasible miRNA vectors. The miR-196a I/DEAC-PNAG-FA nanocomposite improves the stability of miRNA and cell uptake, allowing miRNA to be separated from the complex, inhibiting miR-196a translation, and regulating the expression of apoptotic proteins. MiR-196a I/ DEAC-PNAG-FA has higher efficiency on inhibiting TV and weight compared to free miR-196a inhibitors in the xenotransplantation animal model. This study indicates that DEAC-PNAG-FA is a feasible miRNA vector, which may provide a new and effective method for liver cancer treatment.

Ethics Committee Approval: The Ethics Committee of Shanxi Bethune Hospital approved the experiment and supervised and guided the whole experimental process (No.201909034).
Patient Consent for Publication: Since no clinic experiments have been involved in current study, it unlikely for us to provide the patient consent.

Data Sharing Statement: Author elects to not share data.

Author Contributions: Concept - X.L.; Design - X.L.; Data Collection or Processing: Y.H.; Literature Search-X.L.; Writing - Y.H.

Conflict of Interest: The authors have no conflicts of interest to declare.

Funding: 2017-397-08 Advanced Program of the Science and Technology Activities for the Returned Overseas Chinese Scholars in Shanxi Province; 2016-123 Research Project Supported by Shanxi Scholarship Council of China.

\section{REFERENCES}

1. Huang $\mathrm{C}$, Zhang H, Bai R. Advances in ultrasound-targeted microbubblemediated gene therapy for liver fibrosis. Acta Pharm Sin B. 2017;7:447-452. [CrossRef]

2. Xiong Y, Fang JH, Yun JP, et al. Effects of microRNA-29 on apoptosis, tumorigenicity, and prognosis of hepatocellular carcinoma. Hepatology. 2010;51:836-845. [CrossRef] 
3. Chen Y, Gao DY, Huang L. In vivo delivery of miRNAs for cancer therapy: challenges and strategies. Adv Drug Deliver Rev. 2015;81:128-141. [CrossRef]

4. Slezak-Prochazka I, Durmus S, Kroesen BJ, van den Berg A. MicroRNAs, macrocontrol: regulation of miRNA processing. RNA. 2010;6:1087-1095. [CrossRef]

5. Wan WJ, Qu CX, Zhou YJ, et al. Doxorubicin and siRNA-PD-L1 co-delivery with T7 modified ROS-sensitive nanoparticles for tumor chemoimmunotherapy. Int J Pharm. 2019;566:731-744. [CrossRef]

6. Kubota K, Onishi K, Sawaki K, et al. Effect of the nanoformulation of siRNA-lipid assemblies on their cellular uptake and immune stimulation. Int $J$ Nanomedicine. 2017;12:5121-5133. [CrossRef]

7. Soliman C, Walduck AK, Yuriev E, et al. Structural basis for antibody targeting of the broadly expressed microbial polysaccharide poly- $N$-acetylglucosamine. $J$ Biol Chem. 2018;293:5079-5089. [CrossRef]

8. Luo L J, Huang CC, Chen HC, Lai JY, Matsusaki M. Effect of deacetylation degree on controlled pilocarpine release from injectable chitosan-g-poly (N-isopropylacrylamide) carriers. Carbohyd Polym. 2018;197:375-384. [CrossRef]

9. Erdoğar N, Esendağ $l_{1} \mathrm{G}$, Nielsen TT, et al. Therapeutic efficacy of folate receptortargeted amphiphilic cyclodextrin nanoparticles as a novel vehicle for paclitaxel delivery in breast cancer. $J$ Drug Target. 2018;26:66-74. [CrossRef]

10. Liu MC, Liu L, Wang XR, et al. Folate receptor-targeted liposomes loaded with a diacid metabolite of norcantharidin enhance antitumor potency for $\mathrm{H} 22$ hepatocellular carcinoma both in vitro and in vivo. Int $J$ Nanomedicine. 2016;11:1395-1412. [CrossRef]

11. Mirrahimi M, Hosseini V, Shakeri-Zadeh A, et al. Modulation of cancer cells' radiation response in the presence of folate conjugated $\mathrm{Au} @ \mathrm{Fe}_{2} \mathrm{O}_{3}$ nanocomplex as a targeted radiosensitizer. Clin Transl Oncol. 2019;21:479-488. [CrossRef]

12. Khademi S, Sarkar S, Shakeri-Zadeh A, et al. Corrigendum to "Targeted gold nanoparticles enable molecular CT imaging of head and neck cancer: An in vivo study" [Int. J. Biochem. Cell Biol. 114 (2019) 105554]. Int J Biochem Cell Biol. 2019;120:105695. [CrossRef]

13. Lee KY, Seow E, Zhang Y, Lim YC. Targeting CCL21-folic acid-upconversion nanoparticles conjugates to folate receptor- $\alpha$ expressing tumor cells in an endothelialtumor cell bilayer model. Biomaterials. 2013;34:4860-4871. [CrossRef]

14. Movahedi MM, Mehdizadeh A, Koosha F, et al. Investigating the photo-thermoradiosensitization effects of folate-conjugated gold nanorods on $\mathrm{KB}$ nasopharyngeal carcinoma cells. Photodiagn Photodyn. 2018;24:324-331. [CrossRef]

15. Lu CY, Chen SY, Peng HL, Kan PY, Chang WC, Yen C. Cell-free methylation markers with diagnostic and prognostic potential in hepatocellular carcinoma. Oncotarget. 2017;8:6406-6418. [CrossRef]

16. Hao YX, Wang JP, Zhao LF. Associations between three common MicroRNA polymorphisms and hepatocellular carcinoma risk in Chinese. Asian Pac J Cancer Prev. 2013;14:6601-6604. [CrossRef]

17. Darda L, Hakami F, Morgan R, Murdoch C, Lambert DW, Hunter KD. The role of HOXB9 and miR-196a in head and neck squamous cell carcinoma. PloS One. 2015;10:e0122285. [CrossRef]
18. Yang L, Peng F, Qin J, Zhou H, Wang B. Downregulation of microRNA-196a inhibits human liver cancer cell proliferation and invasion by targeting FOXO1. Oncol Rep. 2017;38:2148-2154. [CrossRef]

19. van der Ven $\mathrm{CF}, \mathrm{Wu}$ PJ, Tibbitt MW, et al. In vitro 3D model and miRNA drug delivery to target calcific aortic valve disease. Clin Sci. 2017;131:181-195. [CrossRef]

20. Yu M, Xue Y, Ma PX, Mao C, Lei B. Intrinsic ultrahigh drug/miRNA loading capacity of biodegradable bioactive glass nanoparticles toward highly efficient pharmaceutical delivery. ACS Appl Mater Interfaces. 2017;9:8460-8470. [CrossRef]

21. Malik S, Lim J, Slack FJ, Braddock DT, Bahal R. Next generation miRNA inhibition using short anti-seed PNAs encapsulated in PLGA nanoparticles. $J$ Control Release. 2020;327:406-419. [CrossRef]

22. Endo-Takahashi Y, Negishi Y, Nakamura A, et al. Systemic delivery of miR-126 by miRNA-loaded Bubble liposomes for the treatment of hindlimb ischemia. Sci Rep. 2014;4:3883. [CrossRef]

23. Robertson NM, Toscano AE, LaMantia VE, et al, et al. Unlocked Nucleic Acids for miRNA detection using two-dimensional nano-graphene oxide. Biosens Bioelectron. 2017;89:551-557. [CrossRef]

24. Fan Z, Zhu P, Zhu Y, Wu K, Li CY, Cheng H. Engineering long-circulating nanomaterial delivery systems. Curr Opin Biotech. 2020;66:131-139. [CrossRef]

25. El-Khatib AM, Badawi MS, Ghatass ZF, Mohamed MM, Elkhatib M. Synthesize of silver nanoparticles by arc discharge method using two different rotational electrode shapes. J Clust Sci. 2018;29:1169-1175. [CrossRef]

26. Vergote I, Leamon CP. Vintafolide: a novel targeted therapy for the treatment of folate receptor expressing tumors. Ther Adv Med Oncol. 2015;7:206-218. [CrossRef]

27. Koirala N, Das D, Fayazzadeh E, et al. Folic acid conjugated polymeric drug delivery vehicle for targeted cancer detection in hepatocellular carcinoma. J Biomed Mater Res A. 2019;107:2522-2535. [CrossRef]

28. Fernández M, Javaid F, Chudasama V. Advances in targeting the folate receptor in the treatment/imaging of cancers. Chem Sci. 2018;9:790-810. [CrossRef]

29. Jones Buie JN, Zhou Y, Goodwin AJ, et al. Application of Deacetylated Poly-N-Acetyl Glucosamine Nanoparticles for the Delivery of miR-126 for the Treatment of Cecal Ligation and Puncture-Induced Sepsis. Inflammation. 2019;42:170-184. [CrossRef]

30. Pu M, Chen J, Tao Z, et al. Regulatory network of miRNA on its target: coordination between transcriptional and post-transcriptional regulation of gene expression. Cell Mol Life Sci. 2019;76:441-451. [CrossRef]

31. Schanen BC, Li X. Transcriptional regulation of mammalian miRNA genes. Genomics. 2011;97:1-6. [CrossRef]

32. Lambert MP, Terrone S, Giraud G, et al. The RNA helicase DDX17 controls the transcriptional activity of REST and the expression of proneural microRNAs in neuronal differentiation. Nucleic Acids Res. 2018;46:7686-7700. [CrossRef] 